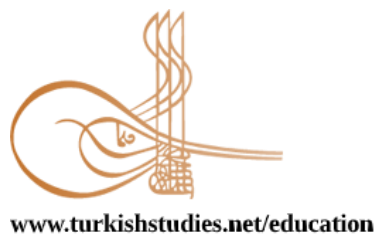

Turkish Studies - Educational Sciences

Research Article / Araştırma Makalesi

\title{
STEM Temelli Uygulamaların Ortaokul Öğrencilerinin Fen Öğrenmeye Yönelik Motivasyonlarma Etkisi
}

\author{
Effect of STEM Based Activities on Motivation of Middle School Students for Science Learning
}

\author{
Emine Kahraman* - Alev Doğan ${ }^{* *}$
}

\begin{abstract}
In this study, the effects of STEM-based activities on students' motivation to learn science were investigated, and the opinions of students about the applied activities were also analyzed. The research group consists of a total of 98 eighth grade students studying in a state middle school in the 2018-2019 academic year. Six classes were included in the research, three experimental groups and three control groups were assigned randomly. The study process was carried out in a total of eight weeks while The Applications of Science. While teaching the experimental group with STEM activities, the control group was applied to the content of the curriculum of the science applications course. The groups were not affected by each other and equal lessons were given in all groups. The study was used as a semi-experimental design with the pretestposttest control group. In the research, "The Questionnaire for Motivation toward Science Learning" was used as a data collection tool, and "Semi-structured Interview Form" was used to determine the students' views on STEM activities during the application process of the experimental group students. The reliability coefficient of the scale used is 0.80 . The semi-structured interview form was developed by the researchers. For the content validity of the questions in the form, ideas of two field education experts and one assessment and evaluation expert were taken. Analysis of the quantitative data collected from the questionnaire for motivation toward science learning made using the t-test for independent groups. Written answers of the students to the semistructured interview form were analyzed by content analysis, which is one of the qualitative analysis methods. As a result of the investigation, it decided that the motivation of the experimental group students was higher than that of the control group students. Additionally, students said that they had the pleasure while STEM activity applications.
\end{abstract}

Structured Abstract: The developments in the fields of science education and teaching in recent years have also been influenced by the educational system and educational contexts of the countries. In direction with these developments, innovative approaches that take into account the needs of the era and individuals have been adopted in the curriculum (Çorlu, Capraro \& Capraro, 2014; Thomas, 2014). Among these approaches,

\footnotetext{
Bu çalışma birinci yazarın doktora tezinden üretilmiştir.

* Arş. Gör., Zonguldak Bülent Ecevit Üniversitesi, Ereğli Eğitim Fakültesi, Matematik ve Fen Bilimleri Eğitimi Bölümü Res. Asst. Zonguldak Bulent Ecevit University, Ereğli Faculty of Education, Mathematics and Sciences Department ORCID 0000-0002-0721-9545 eminekahraman07@gmail.com

** Prof. Dr., Gazi Üniversitesi, Gazi Eğitim Fakültesi, Matematik ve Fen Bilimleri Eğitimi Bölümü

Prof. Dr., Gazi University, Gazi Faculty of Education, Mathematics and Sciences Department

ORCID 0000-0002-8907-1344

alevd@gazi.edu.trdogan.alev@gmail.com
}

Cite as/ Atıf: Kahraman, E. \& Doğan, A. (2020). STEM temelli uygulamaların ortaokul öğrencilerinin fen öğrenmeye yönelik motivasyonlarına etkisi. Turkish Studies - Education, 15(4), 2691-2708. https://dx.doi.org/10.47423/TurkishStudies.42898

Received/Geliş: 14 April/Nisan 2020

Accepted/Kabul: 27 August/Ağustos 2020

Copyright (C) INTAC LTD, Turkey

Checked by plagiarism software Published/Yayın: 30 August/Ağustos 2020 CC BY-NC 4.0 
especially the STEM education approach draws attention (Akgündüz et.al 2015). For this reason, the STEM approach has taken place in many countries' educational programs, from pre-school to higher education. In our country, it is observed that this approach has lately been included in the teaching-learning process and its applications have been enriched (Avan, Gülgün, Yılmaz \& Doğanay, 2019).

Planning the teaching process and making concrete applications with STEM activities are the applications that support the motivation of the student especially for learning science (Küçük \& Şişman, 2017; Means et.al 2016; Mohr Schroeder et.al 2014; Ugras, 2018). In their study, Vennix, den Brok and Taconis (2018) stated that there were positive developments in the motivation of the students participating in STEM supported education programs. Similarly, Hallak, Armoni, and Ben-Ari (2015) stated that in-class activities with students increased the motivation of students at a high level. Because STEM applications allow students an interactive environment that they can experience by learning by doing. Therefore, in this study, it was aimed to investigate the effects of STEM activity practices on the motivation of middle school students to learn science. Also, students' views on the activities implemented within the scope of the process were analyzed.

In this study, a semi-experimental pattern with the pretest-posttest control group was used. The research group consists of a total of 98 eighth grade students studying in a state middle school in the 20182019 academic year. Six classes were included in the research, three experimental groups and three control groups were assigned randomly. The study process was carried out in a total of eight weeks while The Applications of Science. While teaching the experimental group with STEM activities, the control group was applied to the content of the curriculum of the science applications course. The groups were not affected by each other and equal lessons were given in all groups.

In the research, "The Questionnaire for Motivation toward Science Learning" was used as a data collection tool, and "Semi-structured Interview Form" was used to determine the students' views on STEM activities during the application process of the experimental group students. "The Questionnaire for Motivation toward Science Learning" was developed by Dede and Yaman (2008). The reliability coefficient of the scale used is 0.80 . "Semi-structured Interview Form" was developed by the researchers. For the content validity of the questions in the form, ideas of two field education experts and one assessment and evaluation expert were taken.

Quantitative data were analyzed with SPSS package program in this study. Analysis of the quantitative data collected from the questionnaire for motivation toward science learning made using the t-test for independent groups. Written answers of the students to the semi-structured interview form were analyzed by content analysis, which is one of the qualitative analysis methods. The data analyzed in the research were evaluated twice at different times by the same rater. As an end of this evaluation, the reliability value of MilesHuberman (Miles \& Huberman, 1994) was calculated as 95.00.

According to the research findings, data analysis showed that there was a significant difference between the motivation of the experimental and control group students on learning science in favor of the experimental group. Furthermore, there is a significant difference between the motivation of the experiment group students to learn science between the pre-test and post-test scores. It is seen that the motivation of the control group students towards learning science does not differ significantly between the pre-test and post-test scores. According to these results, it can be said that the STEM application process contributed positively to the motivation of the students in the experimental group. The STEM activities carried out attracted the attention of the students as they solved a problem that existed in daily life and produced a product. Besides, the activities were interesting for the students as they used their engineering skills in the product design process.

Changing educational philosophies, the importance of educational environments that emphasize the individual differences of students in education and training environments, prioritize their active role in classroom environments and include group work has started to be understood (MEB, 2018). Therefore, it has become important to enrich the teaching environments with different student-centered applications and to make applications that affect students' motivation towards science. Similar investigations in the literature support the results of our research (Gökbayrak \& Karışan, 2016; Green, 2012; Kang, Ju \& Jang, 2013; Karahan, Canbazoğlu Bilici \& Ünal, 2015; Park \& Yoo, 2013). Again, in a study in which STEM activities conducted by Sarı and Yazicı (2018) were integrated into the $6 \mathrm{E}$ learning model, in the fifth-grade science course, it was studied on the subjects of force, friction force, electricity, and natural phenomena. As a result of this study, it is concluded that the applications positively impact students' motivation towards science. Besides, in the study 
of Uğraş (2018) with seventh-grade students on STEM activities, it was determined that students were more motivated for their lessons, their interest in STEM fields increased and these practices created awareness in science fields.

In our study, the experimental group students whose motivation to learn science increased as a result of the implementation of STEM activities stated that they learned in a fun classroom environment with their friends during the implementation of the activities. During the application process in the activities for each activity, students actively participated in solved a problem and made designs with their group friends for the solution to the problem.

Keywords: Science Education, STEM, STEM activities, Motivation, Student Opinions

Öz: Bu çalışmada, STEM temelli etkinliklerle yapılan uygulamaların öğrencilerin fen öğrenmeye yönelik motivasyonlarına etkisi araştırılarak, öğrencilerin uygulanan etkinliklere yönelik görüşleri belirlenmiştir. Araştırma ön-test son-test kontrol gruplu yar1-deneysel desendir. Araştırma grubuna, bir devlet ortaokulunda son sınıfta öğrenim gören, toplam 98 sekizinci sınıf öğrencisi oluşmaktadır. Araştırmaya altı sınıf dahil edilmiş olup, bu sinıflardan üç deney grubu ve üç kontrol grubu seçkisiz olarak atanmış ve araştırma süreci, bilim uygulamaları dersinde sekiz haftada gerçekleştirilmiştir. Deney grubuna STEM etkinlikleriyle öğretim uygulanırken, kontrol grubuna bilim uygulamaları dersi öğretim programı içeriği uygulanmıştır. Gruplar birbirinden etkilenmeyerek, tüm gruplarda ders süreleri eşit şekilde işlenmiştir. Araştırmada veri toplama aracı olarak "Fen Öğrenmeye Yönelik Motivasyon Ölçeği " ve deney grubu öğrencilerinin uygulama sürecinde STEM etkinliklerine yönelik öğrenci görüşlerini belirlemek için "Yarı-yapılandırılmış Görüssme Formu" kullanılmıştır. Kullanılan ölçeğin güvenirlik katsayısı 0.80 'dir. Yarı-yapılandırılmış görüşme formu araştırmacılar tarafından hazırlanmıştır. Formda bulunan sorularının kapsam geçerliliği için, bir ölçme değerlendirme ve iki alan eğitim uzmanının görüşleri alınmıştır. Fen öğrenmeye yönelik motivasyon ölçeğinden elde edilen nicel verilerinin analizinde bağımsız gruplar t-testi kullanılmıştır. Öğrencilerin yarıyapılandırılmış görüşme formuna verdikleri yazılı cevaplar ise nitel analiz yöntemlerinden içerik analizi ile değerlendirilmiştir. Araştırmanın sonucunda, yapılan uygulamanın deney grubu öğrencilerinin fen öğrenmeye yönelik motivasyonlarını önemli ölçüde arttırdığı söylenebilir. Ayrıca öğrenciler STEM etkinlik uygulamaları sürecinde eğlenerek öğrendiklerini belirtmişlerdir.

Anahtar Kelimeler: Fen Eğitimi, STEM, STEM etkinlikleri, Motivasyon, Öğrenci görüşleri

\section{Giriş}

Son yıllarda fen eğitimi ve öğretimi alanlarında meydana gelen değişimler, ülkelerin eğitim sistemlerini ve öğretim ortamlarını etkilemiştir (Gelen, 2017; Uluyol \& Eryılmaz, 2015). Bu gelişmeler doğrultusunda öğretim programlarında da çağın ve bireylerin ihtiyaçlarını göz önünde bulunduran yenilikçi yaklaşımlar benimsenmiştir (Çorlu, Capraro \& Capraro, 2014; Thomas, 2014). $\mathrm{Bu}$ yaklaşımlar arasında özellikle STEM eğitimi yaklaşımı dikkat çekmektedir (Akgündüz vd., 2015). Bu nedenle, STEM yaklaşımı, birçok ülkenin okul öncesi öğretimden yükseköğretime kadar öğretim programlarında farklı uygulamalarla yer almıştır. Ülkemizde de son zamanlarda bu yaklaşımın öğretme-öğrenme süreci içerisinde dahil edildiği ve uygulamalarının zenginleştiği görülmektedir (Avan, Gülgün, Yılmaz \& Doğanay, 2019).

STEM eğitimi günlük yaşamda varolan problemlere farklı disiplinlerin (fen, teknoloji, mühendislik ve matematik), bilgi ve becerisini kullanarak çözüm üretilmesini sağlar (Merrill, 2009; Smith \& Karr-Kidwell, 2000; Wang, Moore, Roehrig \& Park, 2011). Bireyler bu beceriler arasındaki ilişkileri fark eder ve problemlere farklı bakış açılarıyla yaklaşarak pratik uygulamalar yapar (NRC, 2011). Öğretim etkinlikleri kapsamında yapılan STEM uygulamalarıyla öğrencilerde; 21. yüzyıl becerilerinin kazandırılmasını ve STEM alanlarına yönelik öğrencilerin becerileri ve ilgilerinin arttırılmasına odaklanılmaktadır (Ayar, 2015; 2016; Gökbayrak \& Karışan, 2017; Karakaya, Avgıın \& Yılmaz, 2018). STEM eğitimi öğrencilerin araştırma ve sorgulama yapması, problem çözme ve 
eleştirel düşünme becerisinin geliştirilmesi, etkili iletişim becerilerinin kullanılarak işbirliği içinde özgün bir ürün tasarımının yapılması uygulamalarını da içermektedir (Buyruk \& Korkmaz, 2016).

STEM eğitiminin uygulama sürecinde, fen ve matematik alan uygulamaları yapılırken, bu sürece teknoloji ve mühendislik alan uygulamalarıyla eş zamanlı olarak tasarım uygulamaları da dahil edilir (Kang, Kim \& Kim, 2013). Bu uygulamalar, öğrencilerin bir problem karşısında kendi bilgileriyle çözüm üretmesini tetiklerken, öğrenme becerilerini de geliştirerek anlamlı öğrenmeyi sağlar (Wang, 2012).

Moore vd., (2014) öğrencilerin öğrenme ortamlarına 21. yüzyıl için geçerli olan eğitim uygulamalarını ve öğrenci becerilerini dahil ederek öğrencilerin karmaşı problemlere çözüm önerisi getirmelerine katkılar sağlanabileceğini belirtmişlerdir. Böyle uygulamaların öğrencilerin motivasyonlarını ve akademik başarılarını da olumlu bir şekilde etkilediği vurgulanmaktadır (Elmalı \& Balkan Kıyıcı, 2017; Herdem \& Ünal, 2018; Yıldırım, 2016).

Motivasyon bireyde bir davranışın oluşmasını, bu davranışın yönlendirilmesini ve sürdürülmesini sağlayan içsel ve dışsal etmenlerin tamamını içeren duyuşsal bir yapıdır (Arık, 1996; Martin \& Briggs, 1986) ve bireyin bir davranışla ilgili performansını belirler (Huss-Keeler, Peters \& Moss, 2013; Visser-Wijnveen, Stes \& Petegem, 2012). Özellikle motivasyon; 21. yüzyılda öğrencilerin karmaşık hayat problemlerinin çözümünde, öğrenme becerilerinin ve yeteneklerinin geliştirilmesinde öğretim ortamlarında öğrenmeyi etkileyen en önemli faktörlerden birisidir (Harlen \& Crick, 2003). Motivasyon öğrencilerin akademik başarılarını, onların yaratıcılıklarını ve öğrenme stillerini de etkiler (Kuyper, van der Werf \& Lubbers, 2000; Spitzer, 1996; Wolters, 1999). Bu nedenle bireylerin başarılarının da önemli bir değişkeni olarak kabul edilmektedir (Freedman, 1997; Khamis, Dukmak \& Elhoweris, 2008; Lee \& Brophy, 1996). Literatürde yapılan çalışmalar motivasyonları artan öğrencilerin akademik başarılarının da arttığı belirtilmiştir (Garcia \& Pintrich 1992; Teoh, Koo \& Singh, 2010; Tuan, Chin \& Shieh, 2005; Van De Gaer vd., 2009; Yılmaz \& Çavaş 2007). Hatta literatürde bireyde motivasyonun yükselmesiyle başarının artmasının bireyin öğrenmeye daha çok istekli olmasından kaynaklandığı belirtilmektedir (Li \& Pan, 2009). Ayrıca yapılan bazı çalışmalar da göstermektedir ki; bireylerin öğrenmeye yönelik motivasyonlarının azalmasıyla birlikte bireyin başarısında da azalma meydana gelmektedir (Anderman \& Midgley, 1997; Wigfield \& Wentzel, 2007).

$\mathrm{Bu}$ nedenle öğrencilerin motivasyonunu olumlu yönde etkileyen ve arttıran sinıf içi uygulamaların öğretme sürecinde yapılması önem kazanmaktadır. Yılmaz ve Çavaş (2007) da bireylerin motivasyonlarının çok boyutlu olduğunu vurgulamışlar ve motivasyonun; öğretim ortamlarının özelliklerinden, kullanılan yöntemlerden, öğretmen ve öğrencinin bireysel farklılıklarından etkilendiğini belirtmiştir. Bununla birlikte yapılan araştırmalarda bireyin özellikle fen öğrenimine yönelik motivasyonlarını arttırmak için, öğretim ortamlarında bireyi sınıf ortamında aktif tutacak uygulamalı yöntemlerin kullanılmasının önemi vurgulanmaktadır (Lee \& Brophy, 1996; Tuan, Chin \& Shieh, 2005). STEM etkinleriyle fen öğretimi sürecini planlamak ve somut uygulamalar yapmak öğrencinin özellikle feni öğrenmeye yönelik motivasyonu destekleyen uygulamalardır (Küçük \& Şişman, 2017; Means, Wang, Young, Peters \& Lynch, 2016; Mohr Schroeder vd., 2014; Ugras, 2018). Vennix, den Brok ve Taconis (2018) yaptıkları çalışmalarında, STEM destekli eğitim programlarına katılan öğrencilerin fene yönelik motivasyonlarında olumlu gelişmeler olduğunu ifade etmişlerdir. Benzer şekilde Hallak, Armoni ve Ben-Ari (2015)'de öğrencilerle birlikte yapılan sınıf içi etkinliklerin, öğrencilerin fen motivasyonlarını yüksek düzeyde arttırdığını belirtmişlerdir. Çünkü STEM uygulamalarıyla yapılan öğretim öğrencilerin yaparak yaşayarak kendilerinin deneyimleyecekleri interaktif bir ortam sunar.

$\mathrm{Bu}$ nedenle, bu araştırmada STEM etkinlikleri uygulamalarının ortaokul öğrencilerinin fen öğrenmeye yönelik motivasyonlarına etkisinin araştırılması amaçlanmıştır. Araştırmanın problemi ise "STEM uygulamalarının öğrencilerin fen öğrenmeye yönelik motivasyonlarına etkisi var mıdır?" 
olarak belirlenmiştir. Ayrıca öğrencilerin süreç kapsamında uygulanan etkinliklere yönelik görüşleri de incelenmiştir.

\section{Yöntem}

\section{Araştırma Deseni}

$\mathrm{Bu}$ çalışmada ön-test son-test kontrol gruplu yarı-deneysel desen kullanılmıştır. Deneysel olarak uygulanan çalışmalarda ön-test ve son-testten toplanan verilere göre uygulanan tekniğin etkisi araştırılır. Yarı deneysel desenlerde ise araştırmacı var olan grupları kullanabilir, bu da araştırmacıya zaman ve işgücü kolaylığı sağlar (Büyüköztürk, 2013).

\section{Çalışma Grubu}

Araştırma, 2018-2019 eğitim-öğretim yılında bir devlet ortaokulunda son sınıfta öğrenim gören, toplam 98 sekizinci sınıf öğrencisi oluşmaktadır. Araştırmaya altı sınıf dahil edilmiş olup, bu sinıflardan üç deney grubu ve üç kontrol grubu seçkisiz olarak atanmıştır. Kontrol grubunda bulunan üç sınıfta; A sınıfında (16), B sınıfinda (17) ve C sınıfinda (15) olmak üzere toplam 48 (21 kız ve 27 erkek) öğrenci bulunmaktadır. Deney grubunda bulunan üç sınıfta; D sınıfinda (19), E sınıfında (16) ve F sınıfında (15) olmak üzere toplam 50 (26 kız ve 24 erkek) öğrenci bulunmaktadır. Deney ve kontrol grubunun denkliği için bir önceki eğitim öğretim yılına ait yılsonu genel başarı puan ortalamaları ile fen bilimleri dersi başarı puan ortalamaları karşılaştırılmış ve grupların denk olduğu bulunmuştur. Grupların bir önceki eğitim öğretim yılı yılsonu fen bilimleri dersi başarı puan ortalamaları Tablo 1'de ve genel başarı puan ortalamaları Tablo 2'de verilmiştir.

Tablo 1: Deney ve Kontrol Gruplarının Yedinci Sınıf Fen Bilimleri Dersi Yı1 Sonu Başarı Puan

\begin{tabular}{ccccccc}
\multicolumn{7}{c}{ Ortalamas1 } \\
\hline Grup & $\mathrm{N}$ & $\overline{\mathrm{x}}$ & $\mathrm{s}$ & $\mathrm{sd}$ & $\mathrm{t}$ & $\mathrm{p}$ \\
\hline Deney & 50 & 78.06 & 16.23 & 96 & 1.524 & $.13^{*}$ \\
Kontrol & 48 & 82.46 & 11.91 & & &
\end{tabular}

Tablo 1'de deney ve kontrol gruplarının yedinci sınıf fen bilimleri dersi başarıları arasında anlamlı bir farklılık olmadığı bulunmuştur $\left(\mathrm{t}_{(96)}=1.524, \mathrm{p}>.05\right)$. Buna göre grupların yedinci sınıf fen bilimleri dersi yılsonu başarı puanları açısından denk oldukları söylenebilir.

Tablo 2: Deney ve Kontrol Gruplarının Yedinci Sınıf Y11 Sonu Genel Başarı Puanı Ortalamaları

\begin{tabular}{ccccccc}
\hline Grup & $\mathrm{N}$ & $\overline{\mathrm{x}}$ & $\mathrm{s}$ & $\mathrm{sd}$ & $\mathrm{t}$ & $\mathrm{p}$ \\
\hline Deney & 50 & 80.74 & 13.64 & \multirow{2}{*}{96} & \multirow{2}{*}{.210} & \multirow{2}{*}{$.83^{*}$} \\
Kontrol & 48 & 81.27 & 11.25 & & & \\
\hline
\end{tabular}

*p>.05

Tablo 2'de deney ve kontrol gruplarının yedinci sınıf yılsonu genel başarıları arasında anlamlı bir farklılık olmadığ bulunmuştur $\left(\mathrm{t}_{(96)}=.210, \mathrm{p}>.05\right)$. Buna göre grupların yılsonu başarı puanları açısından denk oldukları söylenebilir.

\section{Veri Toplama Araçları}

Araştırmada, nicel veriler için gerekli izinleri alınan Fen Öğrenmeye Yönelik Motivasyon Ölçeği (FÖYMÖ) ve nitel veriler için araştırmacılar tarafından geliştirilen yarı-yapılandırılmış görüşme formu veri toplama araçları olarak kullanılmıştır.

\section{Fen Öğrenmeye Yönelik Motivasyon Ölçeği (FÖYMÖ)}

FÖYMÖ'yü, Dede ve Yaman (2008) geliştirmiştir. Ölçeğin pilot uygulaması 183 ilköğretim öğrencisi ile yapılmıştır. Pilot uygulama sonrasında, yapılan değişikliklerle 421 ilköğretim 
öğrencisine uygulanmıştır. Ölçek, toplam 23 maddeden oluşmuştur ve güvenirlik katsayısı 0.80 olarak belirlenmiştir. Ölçek beşli Likert tipinde olup, beş alt boyuttan oluşmaktadır. Ölçeğin alt boyutlar1; "araştırma yapmaya yönelik motivasyon", "performansa yönelik motivasyon", "iletişime yönelik motivasyon", "işbirlikli çalışmaya yönelik motivasyon" ve "katılıma yönelik motivasyon"dur. Ölçeğin oluşturulan son hali test-tekrar-test yöntemi gereğince, örneklemde tekrar uygulanmış ve iç tutarlılık katsayısı 0.82 olarak bulunmuştur. Ölçeğin Cronbach alfa iç tutarlık katsayısı 0.7 'den yüksek olduğu için ölçeğin iç tutarlılığın yüksek ve güvenilir olduğu söylenebilir (Field, 2005).

\section{Yarı-yapılandırılmış Görüşme Formu}

Araştırmada nitel veri toplama aracı; öğrencilerin uygulama süreci etkinlikleriyle ilgili görüşlerini ortaya çıarmak için kullanılan yarı-yapılandırılmış görüşme formudur (Yıldırım \& Şimşek, 2005). Yarı-yapılandırılmış görüşme formunu araştırmacılar hazırlamıştır. Formda bulunan sorularının kapsam geçerliliği için, iki alan eğitim uzmanı ve bir ölçme değerlendirme uzmanının görüşleri de alınmıştır. Görüşme formu deney grubu öğrencilerine 30 dakikalık sürede uygulanmıştır.

Yar1-yapılandırılmış görüşme formu içerisinde yer alan sorular:

- Uygulama sürecinde; en beğendiğiniz ve severek yaptığınız etkinlikler hangisidir? Gerekçelerinizi yazınız ve açıklayınız.

- Uygulama sürecinde en beğenmediğiniz etkinlikler hangisidir? Gerekçelerinizi yazınız ve açıklayınız.

\section{Uygulama Süreci}

Araştırma Bilim Uygulamaları dersinde, haftada iki ders saati olmak üzere toplam 8 haftada gerçekleştirilmiştir. Hem deney hem de kontrol grubunda uygulamalar araştırmacı tarafindan yapılmıştır. Kontrol grubu öğrencileri için “Bilim Uygulamaları Dersi Öğretim Programı”na uygun olarak öğretim süreci planlanmıştır (MEB, 2018). Deney grubuna STEM etkinlikleriyle öğretim uygulanırken, kontrol grubuna bilim uygulamaları dersi öğretim programı içeriği uygulanmıştır. Gruplar birbirinden etkilenmeyerek, tüm gruplarda ders süreleri eşit şekilde dersler gerçekleştirilmiştir. Deney grubu öğrencilerine yapılan ön bilgilendirmelerden sonra öğrenciler Tablo 3'de verilen STEM etkinliklerini 4-5 kişilik gruplar halinde sınıf içerisinde gerçekleştirmiştir. Uygulamalarda probleme dayalı bir öğrenme süreci yürütülmüştür (Koçakoğlu, 2010). Öğrencilere problemler verilerek olası çözümler için plan yapmaları istenmiştir. Bu süreçte grup üyeleri arasında beyin firtınası yapılarak çözüm önerileri ve fikirler geliştirilmiş ve en uygun çözümler belirlenmiştir. Grup içerisinde yapılan tartışmalar sonucunda grup üyeleri arasında iş bölümü yapılarak tasarım süreci planlanmış ve tasarımlar oluşturulmuştur. Son aşamada, tüm gruplar diğer gruplarla birlikte tasarımlar hakkında görüşlerini ifade etmişlerdir. Tasarımlarda gerekli görülen iyileştirmeler yapılarak tasarımlar sunulmuştur. Bu süreçte araştırmacılar öğrenci gruplarına rehberlik görevi yapmıştır. Uygulama süreci sonrasında etkinliklere yönelik olarak görüş formu ile öğrenci görüşleri alınmıştır.

Etkinliklerin oluşturulması aşamasında STEM uygulamalarına yönelik alan yazın taraması yapılmıştır. Etkinlikler STEM uygulama özelliklerini taşıyacak şekilde düzenlenerek, üç fen eğitimi alan uzmanı tarafından, uzman görüşü alınıp uygulanabilir hale getirilmiştir. Deney ve kontrol grubu öğrencilerine Fen Öğrenmeye Yönelik Motivasyon Ölçeği uygulama süreci öncesi ve sonrasında ayrı ayrı uygulanmıştır. Uygulama süreci için hazırlanan STEM etkinlikleri Tablo 3'te verilmiştir. 


\begin{tabular}{|c|c|c|}
\hline \multicolumn{3}{|c|}{ Tablo 3: STEM Etkinlikleri } \\
\hline Etkinlik Adı & Etkinlik Amacı & ${ }^{*}$ Kazanımlar \\
\hline $\begin{array}{l}\text { Suyu } \\
\text { Temizleyelim } \\
\text { (2 ders saati) }\end{array}$ & $\begin{array}{l}\text { Etkinlikte öğrenciler } \\
\text { atık suyun arıtımı için } \\
\text { bir su arıtım sistemi } \\
\text { tasarımı yapar (Kuvaç } \\
\text { \& Koç Sarı, 2018). }\end{array}$ & $\begin{array}{l}\text { "Sıvı atıkların geri dönüşümüne yönelik çözümler önerir" } \\
\text { "Bilimsel bilgiye ulaşırken bilimsel araştırma basamaklarını } \\
\text { kullanır" } \\
\text { "Sıvı atıkların geri dönüşümüne yönelik proje tasarlar ve ürün } \\
\text { oluşturur" } \\
\text { "Yakın çevresine yönelik atık kontrolü sorumluluğu geliştirir" }\end{array}$ \\
\hline $\begin{array}{l}\text { Termos } \\
\text { yapalım } \\
\text { (2 ders saati) }\end{array}$ & $\begin{array}{l}\text { Etkinlikte öğrenciler } \\
\text { gidaların soğuk ve } \\
\text { sicak kalması için bir } \\
\text { termos tasarımı } \\
\text { yaparlar (Science Fair } \\
\text { Central, 2018). }\end{array}$ & $\begin{array}{l}\text { "Çevresinde varolan 1Sı yalıtım malzemelerinin farkına varır ve } \\
\text { seçilme ölçütlerini bilir" } \\
\text { "Alternatif ısı yalıtım malzemelerini diğer maddelerden ayırt } \\
\text { eder" } \\
\text { "Problemi çözmek için veri toplama araçlarını kullanarak } \\
\text { yapılacak temel işlemleri yapar" } \\
\text { "Günlük yaşamda varolan bir ürünün mekanik özelliklerini } \\
\text { bilerek yeniden tasarımını yapar." }\end{array}$ \\
\hline $\begin{array}{l}\text { Kendi } \\
\text { Uydunu Yap } \\
\text { Ve Firlat } \\
\text { (2 ders saati) }\end{array}$ & $\begin{array}{l}\text { Etkinlikte öğrenciler } \\
\text { bir uydu tasarlayacak } \\
\text { ve bu uydularını } \\
\text { firlatmak için bir } \\
\text { sistem } \\
\text { geliştireceklerdir (The } \\
\text { NASA BEST } \\
\text { Activities Guide, } \\
\text { 2011). }\end{array}$ & $\begin{array}{l}\text { "Uydunun yapısını ve kullanım amaçlarının farkına varır" } \\
\text { "Bilimin gelişiminde uydunun öneminin farkına varır" } \\
\text { "Öğrenci ürün geliştirme sürecinde takım çalışmasının önemini } \\
\text { kavrar" } \\
\text { "Ürün tasarımında geometrik şekillerin özelliklerini kavrar" } \\
\text { "Basit bir uydu modeli oluşturur" }\end{array}$ \\
\hline $\begin{array}{l}\text { Evimizi } \\
\text { Işıklandıralım } \\
\text { (2 ders saati) }\end{array}$ & $\begin{array}{l}\text { Etkinlikte öğrenciler } \\
\text { elektrik devrelerindeki } \\
\text { pil ve lamba sayısını } \\
\text { değiştirerek bir ev } \\
\text { tasarımı yapar ve bu } \\
\text { evin elektrik sistemini } \\
\text { oluşturur (Yalaki, } \\
\text { 2016). }\end{array}$ & $\begin{array}{l}\text { "Elektrik devre elemanlarını günlük hayattaki bir probleme } \\
\text { yönelik çözüm üretirken pratik yapar" } \\
\text { "Ampullerin farklı bağlandığı durumlardaki parlaklıklarını } \\
\text { devre üzerinde taslağını yaparak çıkarımda bulunur" } \\
\text { "Tasarım sürecinde neden sonuç ilişkisi kurar" } \\
\text { "Bireysel ve toplumsal ihtiyaçların karşılanmasında bilimin } \\
\text { rolünü fark eder" } \\
\text { "Işıklandırılmış bir ev tasarımı yapar" }\end{array}$ \\
\hline $\begin{array}{l}\text { Farkli } \\
\text { Devreler } \\
\text { (2 ders saati) }\end{array}$ & $\begin{array}{l}\text { Etkinlikte öğrenciler } \\
\text { günlük hayatta } \\
\text { kullandıkları } \\
\text { malzemeleri } \\
\text { kullanarak farklı } \\
\text { elektrik devreleri } \\
\text { tasarlayacaklardır } \\
\text { (Science Fair Central, } \\
\text { 2018). }\end{array}$ & $\begin{array}{l}\text { "Bir elektrik devresinde ampulün parlaklığını bağlı olduğu } \\
\text { değişkenleri test eder" } \\
\text { "Elektrik devre elemanlarını farklı uygulamalar üzerinde test } \\
\text { eder ve gözlemlerde bulunur" } \\
\text { "Problemin çözümünden elde ettiği verilerle çıkarım yaparak } \\
\text { bilgisini organize eder" } \\
\text { "Elektrik devresi tasarlar" } \\
\text { "Etkinlik sonunda neden sonuç ilişkisi kurar" }\end{array}$ \\
\hline $\begin{array}{l}\text { Serada Çilek } \\
\text { Üretelim } \\
\text { (2 ders saati) }\end{array}$ & $\begin{array}{l}\text { Etkinlikte öğrenciler } \\
\text { fotosentez olayını } \\
\text { etkileyen faktörleri } \\
\text { belirlemek için bir } \\
\text { çilek serasının } \\
\text { tasarımı yapılacaktır } \\
\text { (MEB, 2019). }\end{array}$ & $\begin{array}{l}\text { "Sıcaklığın, su miktarının, karbondioksit miktarının, ışık } \\
\text { şiddetinin ve ışık renginin fotosentez sürecine etkisini araştırır" } \\
\text { "Fotosentez hızını etkileyen etmenlere yönelik çıkarımda } \\
\text { bulunur" } \\
\text { "Fotosentezi etkileyen etmenlere yönelik proje tasarlar" } \\
\text { "Günlük hayatta karşılaştığı bir probleme yönelik çözüm önerisi } \\
\text { geliştirir ve geliştirdiği öneriye yönelik ürünün taslağını ve } \\
\text { maketini oluşturur." }\end{array}$ \\
\hline
\end{tabular}

"MEB, (2018) 


\section{Verilerin Analizi}

Araştırmada kullanılan FÖYMÖ'den elde edilen veriler SPSS paket programı kullanılarak analiz edilmiştir. Deney ve kontrol gruplarının verilerinin analizi sürecinde; grupların son-test puanlarını daha iyi yorumlayabilmek için, her iki grubun son-test ve ön-test puanları arasındaki farkın, yani erişilerin anlamlı olup olmadığına bakılmıştır (Akdağ \& Tok, 2010). Araştırmanın verilerinde, analiz öncesi normallik varsayımları test edilmiş olup, deney ve kontrol gruplarının test verileri normallik varsayımlarını sağladığına ulaşılmıştır. Bu testlerin Shapiro-Wilks analizi sonucunda anlamlılık düzeyi .05 'ten büyük çıkmış olup, testlere ait puanların normal dağılım gösterdiği söylenebilir (Büyüköztürk, 2013). Bu sonuca göre, deney ve kontrol grupları arasında fen öğrenmeye yönelik motivasyon değişkeni arasında anlamlı bir farklılık olup olmadığını test etmek amacıyla, elde edilen veriler bağımsız gruplar için t-testi ile analiz edilmiştir. Deney ve kontrol gruplarının kendi içinde ön-test ve son-test puanları arasındaki farklılığı test etmek için de bağımlı gruplar için t-testi kullanılmıştır. Araştırmaya ait bulgular, anlamlılık düzeyi en düşük .05 kabul edilmiş ve yorumları yapılmıştır.

Öğrencilerin yarı-yapılandırılmış görüşme formuna verdikleri yazılı cevapların analizinde içerik analizi kullanılmıştır (Özdemir, 2010). Öğrencilerin görüşme formundaki sorulara verdikleri cevaplara göre kodlar oluşturulmuştur. Öğrencilerin her bir etkinliğe yönelik birden fazla görüşü bulunabilmektedir. Öğrencilerin verdikleri cevaplara göre oluşturulan kodların, katılımcıların bu görüşleri tekrar etme sıklığına göre frekans değerleri verilmiştir. Kodlar tablolar oluşturularak en yüksek frekans değerinden, en düşük frekansa doğru sıralanmıştır. Araştırmada içerik analizine tabi tutulan veriler, aynı puanlayıcı tarafindan farklı zamanlarda iki defa değerlendirilmiş olup MilesHuberman (Miles \& Huberman, 1994) güvenirlik değeri 95.00 olarak hesaplanmıştır. Öğrencilerin sorulara verdikleri cevaplardan doğrudan alıntılanmalar yapılarak bulgular desteklenmiştir. Araştırma bulgularında öğrencilerin etkinliklere yönelik görüşleri ifade edilirken öğrenciler Ö1, Ö2 şeklinde kodlanmıştır.

\section{Çalışmanın Etik İzni}

Yapılan bu çalışmada "Yükseköğretim Kurumları Bilimsel Araştırma ve Yayın Etiği Yönergesi” kapsamında uyulması belirtilen tüm kurallara uyulmuştur. Yönergenin ikinci bölümü olan "Bilimsel Araştırma ve Yayın Etiğine Aykırı Eylemler" başlığı altında belirtilen eylemlerden hiçbiri gerçekleştirilmemiştir.

\section{Etik kurul izin bilgileri} Etik Kurulu

Etik değerlendirmeyi yapan kurul adı = T.C. Bülent Ecevit Üniversitesi İnsan Araştırmaları

Etik değerlendirme kararının tarihi $=04.02 .2019$

Etik değerlendirme belgesi sayı numarası $=490$

\section{Bulgular ve Yorumlar}

Araştırmada FÖYMÖ ve yarı-yapılandırılmış görüşme formundan elde edilen bulgular aşağıda verilmiştir. STEM etkinlikleriyle uygulama yapılan deney grubu öğrencilerinin ve öğretim programının öngördüğü şekilde uygulamalarını yapan kontrol grubu öğrencilerinin FÖYMÖ’den aldıkları son-test - ön-test erişi puanları arasındaki anlamlılık düzeyi bağımsız gruplar t-testiyle incelenmiş olup, sonuçlar Tablo 4'de verilmiştir.

Tablo 4: Deney ve Kontrol Gruplarına Ait FÖYMÖ t-testi Sonuçları

\begin{tabular}{ccccccc}
\hline Grup & $\mathrm{N}$ & $\overline{\mathrm{x}}$ & $\mathrm{s}$ & $\mathrm{sd}$ & $\mathrm{t}$ & $\mathrm{p}$ \\
\hline Kontrol & 48 & -.01 & .64 & 96 & 5.306 & $.00^{*}$ \\
Deney & 50 & .55 & .39 & & & \\
\hline$* \mathrm{p}<.05$ & & & & & &
\end{tabular}


Tablo 4 incelendiğinde; deney ve kontrol grubu FÖYMÖ erişi puan (son-test - ön-test) ortalamaları arasında deney grubu lehine anlamlı bir farklılık olduğu görülmektedir $\left(\mathrm{t}_{(96)}=5.306\right.$, $\mathrm{p}<.05)$. FÖYMÖ erişi puanları ortalaması; deney grubu $(\overline{\mathrm{x}}=.55)$ olup, kontrol grubundan $(\overline{\mathrm{x}}=-.01)$ daha yüksektir. $\mathrm{Bu}$ sonuca göre STEM uygulamaları öğrencilerin, fen öğrenmeye yönelik motivasyonlarını olumlu olarak etki ettiği söylenebilir.

Deney grubunun FÖYMÖ ön-test ve son-test puanları arasındaki anlamlılık düzeyi bağımlı gruplar için t-testiyle incelenmiş olup, sonuçlar Tablo 5'de verilmiştir.

Tablo 5: Deney Grubuna Ait FÖYMÖ t-testi Sonuçları

\begin{tabular}{ccccccc}
\hline Ölçüm & $\mathrm{N}$ & $\overline{\mathrm{x}}$ & $\mathrm{s}$ & $\mathrm{sd}$ & $\mathrm{t}$ & $\mathrm{p}$ \\
\hline Ön Test & 50 & 3.84 & .33 & 49 & 10.039 & $.00^{*}$ \\
Son Test & 50 & 4.39 & .25 & & & \\
\hline *p<.05 & & & & & &
\end{tabular}

Tablo 5'e göre deney grubunun FÖYMÖ ön-test puan ortalamalarıla son-test puan ortalamaları arasında son-test lehine anlamlı bir farklıl1k belirlenmiştir $\left(\mathrm{t}_{(49)}=10.039, \mathrm{p}<.05\right)$. Deney grubunun FÖYMÖ puan ortalamas1 son-testi $(\bar{x}=4.39)$, ön-testten $(\bar{x}=3.84)$ daha yüksek bulunmuştur.

Benzer şekilde kontrol grubunun FÖYMÖ ön-testi ve son-testi puanları arasındaki anlamlılık düzeyi bağımlı gruplar t-testiyle incelenmiş olup, sonuçlar Tablo 6'da verilmiş̧ir.

Tablo 6: Kontrol Grubuna Ait FÖYMÖ t-testi Sonuçlanı

\begin{tabular}{ccccccc}
\hline Ölçüm & $\mathrm{N}$ & $\overline{\mathrm{x}}$ & $\mathrm{s}$ & $\mathrm{sd}$ & $\mathrm{t}$ & $\mathrm{p}$ \\
\hline Ön Test & 48 & 4.09 & .51 & 47 & .152 & $.88^{*}$ \\
Son Test & 48 & 4.08 & .42 & & & \\
\hline *p $>.05$ & & & & & &
\end{tabular}

Tablo 6 incelendiğinde kontrol grubunun FÖYMÖ son-test puan ortalaması ( $\bar{x}=4.08)$, öntest puan ortalamasından $(\bar{x}=4.09)$ daha düşük bulunmuştur. Bu sonuçlara göre kontrol grubunun ön-test ile son-test puanları arasında anlamlı düzeyde fark olmadığı bulunmuştur $\left(\mathrm{t}_{(47)}=.152, \mathrm{p}>.05\right)$.

Yapılan nicel analizler sonucunda STEM etkinlikleriyle yapılan öğretim uygulamalarının, öğretim programın öngördüğü uygulamalara göre öğrencilerin fen öğrenmeye yönelik motivasyonlarını arttırdığı söylenebilir. Bu bağlamda, uygulama sürecinde yer alan STEM etkinliklerine yönelik öğrencilerin görüşlerinin incelenmesi için yarı-yapılandırılmış görüşme formuna verdikleri cevaplar nitel bir analiz tekniği olan içerik analiziyle incelenmiştir. Öğrencilerin uygulama sürecinde en beğendikleri etkinliklere ilişkin, öğrencilerden alınan görüşlere ait sonuçlar Tablo 7'de verilmiştir. 
Tablo 7: Uygulama Sürecinde Öğrencilerin En Beğendikleri ve Severek Yaptıkları Etkinliklere İlişkin Kodlar ve Frekanslar

\begin{tabular}{llc}
\hline Etkinlik Adı & Kod & Frekans \\
\hline & Birinci olma & 4 \\
& Başarılı olma & 3 \\
& Eğlenceli & 2 \\
Suyu Temizleyelim (13) & 2 \\
& Yapım aşaması zor ve güzel & 1 \\
& Düşündürücü etkinlik & 1 \\
\hline \multirow{3}{*}{ Termos Yapalım (10) } & Sağlıkla ilgili & 5 \\
& Eğlenceli & 3 \\
& Birinci olma & 2 \\
\hline \multirow{3}{*}{ Kendi Uydunu Yap ve Fırlat } & Yapımı zevkli & 2 \\
(7) & Yenilikçi & 2 \\
& Ufku geliştirici & 2 \\
& Fikir paylaşımına teşvik edici & 1 \\
\hline \multirow{2}{*}{ Evimizi Işılklandıralım (6) } & Eğlenceli & 3 \\
& Işık ve elektrik konusu içermesi & 2 \\
& Önemli bir konu olması & 1 \\
\hline Farklı Devreler (4) & Ögretici & 2 \\
& Diğerlerinden farklı & 2 \\
\hline Serada Çilek Üretelim (2) & Güzel bir etkinlik & 2 \\
\hline
\end{tabular}

Öğrenciler genel olarak tüm etkinliklerden keyif aldıklarını ve eğlenerek öğrendiklerini ifade etmişlerdir. Tablo 7'de öğrencilerin uygulama sürecinde en beğendikleri ve severek yaptıkları etkinliklere yönelik görüşleri incelendiğinde, öğrencilerin en beğendikleri etkinlik "Suyu Temizleyelim" (13) etkinliğidir. Bu etkinliği sırasıyla "Termos Yapalım" (10), "Kendi Uydunu Yap ve Fırlat" (7), "Evimizi Işıklandıralım" (6), "Farklı Devreler" (4) etkinlikleri izlemiş olup, en az beğenilen etkinlik "Serada Çilek Üretelim" (2) etkinliği olmuştur. En çok beğenilen "Suyu Temizleyelim" etkinliğinin beğenilme gerekçesi olarak öğrenciler; genellikle etkinliğin eğlenceli, düşündürücü bir etkinlik olduğunu belirterek sağlıklı yaşam için önemli olduğunu vurgulamışlardır. Öğrencilerin etkinliklere yönelik olarak bildirdikleri görüşlerden bazıları şunlardır:

"Suyu Temizleyelim” etkinliği ile ilişkili öğrenciler: (Ö2): “...Çünkü o etkinlikte çok ĕglendim. Kömürü kullansak mı kullanmasak mı diye kafamız çok karıştı. Beyin firtınası yaptık.”, (Ö35): “...Çünkü yapımı zordu ve daha eğlenceliydi.”, (Ö14): “...Hem yaparken hem de denerken çok eğlendim. ” ve (Ö46): “...Sağgllk için önemli." şeklinde görüş bildirmişlerdir. "Termos Yapalım” etkinliği ile ilişkili bazı öğrenciler: (Ö30): “...yaptığımız tasarım çok sağlamdı, hoşuma gitti.” ve (Ö37): “...Etkinlik süreci çok eğlenceliydi. ” şeklinde görüş bildirmişlerdir.

"Kendi Uydunu Yap ve Fırlat" etkinliği ile ilgili öğrenciler gerekçe olarak; (Ö25): “...Kendimiz arkadaşlarımızla yaptığımızdan ve yenilikçi fikirler bu projemde çıktı." ve (Ö23): “...Uyduyu tasarlamak uydunun üzerine sensör yapmak ufkumu geliştirdi.” ve (Ö21): “...arkadaşlarımızla fikir paylaşımı sağladı, eğlenceli bir dersti çünkü başarılı olduk.” şeklinde görüşlerini ifade etmişlerdir.

"Evimizi Işıklandıralım” etkinliğinde ise öğrenciler gerekçe olarak (Ö10): “...Çünkü o etkinlikte çok eğlendim. ” ve (Ö9): “...Etkinlikte devreleri oluşturmak eğlenceliydi.” şeklinde görüş bildirmişlerdir. "Serada Çilek Üretelim” etkinliğinde ise öğrenciler gerekçe olarak; (Ö20) "... çok ögretici bir uygulama...” ve (Ö26) “... çok eğitici ... ” şeklinde görüş bildirmişlerdir.

Uygulama sürecinde kullanılan ve öğrenciler tarafından beğenilmeyen etkinliklere yönelik alınan görüşler de Tablo 8'de verilmiştir. 
Tablo 8: Uygulama Sürecinde Öğrencilerin En Beğenmedikleri Etkinliklere İlişkin Kodlar ve

\begin{tabular}{llc}
\multicolumn{2}{c}{ Frekanslar } & \\
\hline Etkinlik Adı & Kod & Frekans \\
\hline \multirow{3}{*}{ Farklı Devreler (11) } & Sıkıcı & 4 \\
& İlgisizlik & 3 \\
& Yapamama & 2 \\
& Devre kurmayı sevmeme & 2 \\
\hline \multirow{3}{*}{ Evimizi Işıklandıralım } & Devre kurmayı sevmeme & 4 \\
$(8)$ & Sonuncu olma & 2 \\
& Başarısız olma & 1 \\
& Sıkıcı & 1 \\
\hline Kendi Uydunu Yap ve & Yapamama & 3 \\
Fırlat (6) & Yapım aşamasının zor olması & 1 \\
& Çalışmaması & 1 \\
\hline Termos Yapalım (3) & Sıkıcı & 1 \\
\hline Serada Çilek Üretelim & Yapamama & 1 \\
(2) & & 1 \\
\hline Suyu Temizleyelim (1) & Başarısız olma & 1 \\
\hline
\end{tabular}

Tablo 8'e göre öğrenciler uygulama sürecinde en fazla "Farklı Devreler" etkinliğini beğenmediklerini ifade etmişlerdir. Bunun gerekçesi olarak, bu etkinliğin sıkıcı olduğunu, ilgi çekmeyen bir etkinlik olduğunu, yapamadıklarını ve devre kurmayı sevmediklerini vurgulamışlardır. Öğrencilerin etkinliklere yönelik olarak bildirdikleri görüşlerden bazıları şunlardır:

"Farklı Devreler" etkinliği hakkında görüş bildiren öğrenciler gerekçe olarak (Ö13): “...Farklı devreleri yapmak hiç istemiyordum.”, (Ö35): “...Etkinlik sıkıcıydl.” ve (Ö31): “...Devre kurmayı sevmiyorum." şeklinde görüş bildirmişlerdir. En çok beğenilmeyen etkinliği "Evimizi Işıklandıralım” diye görüş bildiren öğrenciler gerekçe olarak (Ö2): “...Çünkü o etkinlikte hiç eğlenmedim. Zaten sonuncu olmuştuk.” ve (Ö34): “...Devre kurmayl sevmiyorum” şeklinde görüş bildirmişlerdir. "Termos Yapalım" etkinliği hakkında görüş bildiren öğrenciler gerekçe olarak ise; (Ö26): “...Etkinlik sıkıcıydı.” şeklinde görüş bildirmişlerdir. Benzer şekilde "Kendi Uydunu Yap ve Fırlat” etkinliği ile ilgili görüş bildiren öğrenciler de gerekçe olarak (Ö29): “...Yapım aşaması zordu." ve (Ö28): “Arkadaşlarımla orta noktayl zor bulduk." şeklinde görüş bildirmişlerdir.

\section{Sonuç, Tartışma ve Öneriler}

Bu araştırmada, STEM etkinlik uygulamalarının sekizinci sınıf öğrencilerinin fen öğrenmeye yönelik motivasyonlarına etkisi araştırılmış ve öğrencilerin süreç sonundaki etkinliklerle ilgili görüşleri incelenmiştir. Tablo 5 ve 6 incelendiğinde deney grubu öğrencilerinin fen öğrenmeye yönelik motivasyonlarının arttığı görülürken, konrtol grubu öğrencilerinde böyle bir durum gözlenmemiştir. Bununla birlikte Tablo 4'den elde edilen sonuçlara göre de deney grubu öğrencilerinin fen öğrenmeye yönelik motivasyonları kontrol grubuna göre anlamlı düzeyde artmıştır. Kontrol grubu ile yapılan eğitim sürecinde öğrencilerle bilim uygulamaları dersi öğretim programında öngörülen şekilde dersler işlenmiştir. Süreçte daha çok öğretmen merkezli ders işlenmesi ve öğrencilerin derse aktif katılım yerine bilginin pasif alıcısı konumunda görev almaları, öğrencilerin fene yönelik motivasyonlarının aynı düzeyde kalmasının sebebi olabilir. Deney grubunda ise öğrenciler işbirlikçi gruplar halinde çalışarak süreç boyunca yaptıkları etkinliklerde aktif rol alarak kendi öğrenmelerini gerçekleştirmiş̧lerdir. Böylece uygulama sürecinin deney grubu öğrencilerinin fene yönelik motivasyonlarına olumlu katkılar sağladığı söylenebilir.

Eğitim öğretim ortamlarında değişen eğitim felsefelerinin farklılıklar kazanmasıyla, öğrencilerin kendi bireysel farklılıklarını ön plana çıkaran, sınıf ortamlarında aktif rol almasını ön planda tutan ve grup çalışmalarına yer veren öğretim ortamlarının önemi anlaşılmaya başlanmıştır 
(MEB, 2018). Bu nedenle fen bilimlerinde öğrenci merkezli farklı uygulamalarla öğretim ortamlarını zenginleştirerek öğrencilerin fene yönelik motivasyonlarını etkileyen uygulamalar yapmak son derece önemli hale gelmiştir. Literatürde yapılan benzer çalışmalar araştırmamızın sonuçlarını destekler niteliktedir (Gökbayrak \& Karışan, 2016; Green, 2012; Karahan, Canbazoğlu Bilici \& Ünal, 2015; Park \& Yoo, 2013). Yine Sarı ve Yazıcı (2018)'nın yaptı̆̆ı STEM etkinliklerinin 6E öğrenme modeline entegre edildiği bir araştırmada da beşinci sınıf fen bilimleri dersinde kuvvet, sürtünme kuvveti, elektrik ve doğa olayları konuları çerçevesinde çalışılmış ve bu çalışmanın sonucunda da uygulamaların, öğrencilerin fene yönelik motivasyonlarında artış meydana getirdiği sonucuna ulaşılmıştır. Bununla birlikte Uğraş'ın (2018) yedinci sınıf öğrencileriyle bazı STEM etkinlikleri üzerine yaptığı çalışmasında, öğrencilerin derslerine daha motive olduklarını ve STEM alanlarına yönelik ilgilerinin arttığını ve bu uygulamaların fen alanlarına yönelik bir farkındalık oluşturduğu belirlenmiştir.

Literatürde böyle uygulamaların özellikle eğitim-öğretim ortamlarını zenginleştirilmesi nedeniyle öğrencilerin motivasyonlarını olumlu yönde etkilediği özelikle vurgulanmaktadır (Fortus \& Vedder-Weiss, 2014; Kong \& In-Cheol, 2014; Vedder Weiss \& Fortus, 2010). Araştırmamızda da STEM etkinliklerinin uygulanması sonucu fen öğrenmeye yönelik motivasyonları artan deney grubu öğrencileri etkinliklerin uygulama sürecinde arkadaşlarıyla eğlenceli bir sınıf ortamında öğrendiklerini belirtmişlerdir. Uygulama süreci boyunca her bir etkinlik için öğrenciler, aktif olarak etkinliklere katılmış, bir probleme çözüm üretmişler ve problemin çözümüne yönelik grup arkadaşlarıyla tasarımlar yapmışlardır. Öğrenciler özellikle uygulama sürecinin tamamında grup arkadaşlarıyla işbirliği yaparak bir ürün ortaya çıkarmışlardır.

Tablo 7'ye göre öğrencilerin süreç içerisinde en beğendikleri etkinlikler; "Suyu Temizleyelim", "Termos Yapalım" ve "Kendi Uydunu Yap ve Firlat" etkinlikleridir. Bu etkinliklerden "Suyu Temizleyelim" (Kuvaç \& Koç Sar1, 2018) etkinliğinde öğrenciler günlük yaşamda varolan bir probleme yönelik çözüm üreterek ürün ortaya koymuşlardır. "Termos Yapalım" (Science Fair Central, 2018) etkinliğinde öğrenciler günlük hayatta kullandıkları termosların çalışma mekanizmasını öğrenmişler ve termos tasarımı öğrencilere ilginç gelmiştir. "Kendi Uydunu Yap ve Fırlat" (The NASA BEST Activities Guide, 2011) etkinliğinde, öğrencilere başlangıçta bir uydu tasarımı yapma fikri karmaşık gelmiştir. Süreç sonunda ise tasarladıkları uydular onları motive etmiştir. Öğrenciler kendilerini bir mühendis gibi düşünmüşlerdir. "Serada Çilek Üretelim” etkinliği de öğrenciler tarafindan eğitici ve öğretici bulunmuştur. Bu etkinlikte öğrenciler fotosentezi etkileyen faktörleri dikkate alarak bir sera tasarımı ortaya koymuşlardır. Dolayısıyla öğrenciler verilen probleme çözüm üretirken hem tasarım mühendislik becerilerini hem de alan bilgilerini kullanmışlardır. Öğrencilerle yapılan bu etkinliklerde grup çalışmasında her bir öğrenciye rol düştüğü, etkinliklerin günlük hayatla ilişkili, öğretici, eğlenceli etkinlikler olması öğrencilerin motivasyonlarına olumlu katkılar sağlamıştır. Benzer şekilde Baran, Canbazoğlu-Bilici ve Mesutoğlu (2015)'nun 6. sınıf öğrencileriyle yapılan spot oluşturma etkinliğinde, öğrencilerden mühendislik tasarımını kullanarak kendilerine verilen senaryoya uygun spotlar yapmaları istenmiş ve çalışmanın sonunda yapılan etkinliklerdeki esneklik ve eğlencenin öğrencileri motive ettiğ bulunmuştur. Küçük ve Şişman (2017)'ın ilkokul öğrencilerinin robotik uygulamalar üzerine yaptığ 1 bir çalışmada da sürecin eğlenceli ve verimli geçmesi sonucunda öğrencilerin motivasyonlarının arttığı sonucuna ulaşılmıştır.

STEM uygulama süreçlerinde etkinlikler öğrencilerin duyuşsal, psikomotor ve bilişsel boyutta beceri ve başarılarının gelişimine de katkılar sağlamaktadır (Çavaş vd., 2013). Sınıf içinde yapılan bu etkinlikler öğrencilerin farklı alanlardaki öğrenmelerini kolaylaştırarak ilgilerini artırdığ 1 gibi dersleri eğlenceli hale getirir (Demircioğlu, Özmen \& Demircioğlu, 2004; Gelici \& Bilgin, 2011). STEM etkinlikleri disiplinlerarası bir entegrasyon da sağladığı için öğrencilerin derse karş1 motivasyonlarını olumlu yönde etkilemektedir. Araştırmamızda da öğrenciler genel olarak etkinlik 
uygulama sürecinde kendi yeterliklerini de ortaya çıkarmışlar ve bu da onların motivasyonlarına katkı sağlamıştır.

Uygulama sürecinde kullanılan etkinliklerin bazıları ise öğrenciler tarafından daha az ilgi çekmiştir. Tablo 8'de öğrenciler süreç içerisinde en beğenmedikleri etkinlikler arasında "Farklı Devreler" ve "Evimizi Işıklandıralım" etkinliklerini belirtmişlerdir. Bu etkinliklerden "Farklı Devreler" etkinliğinde öğrencilerin günlük hayatta kullanılan farklı malzemelerden elektrik devreleri oluşturmaları gerekmektedir. "Evimizi Işıklandıralım” etkinliğinde ise öğrenciler tasarladıkları bir evi, elektrik devre elemanlarını kullanarak 1şıklandıracaklardır. "Farklı Devreler" ve "Evimizi Işıklandıralım" etkinliklerinin uygulama sürecinde probleme çözüm üretme noktasında öğrencilerin zorluklar yaşadığı ve tasarım yapmaya isteksiz oldukları gözlenmiştir. Literatürde yapılan çalışmalarda da elektrik konusunda ve konu kavramlarının öğretiminde öğrencilerin öğrenmede güçlük yaşadıkları, kavram yanılgılarının olduğu ayrıca konu içerisinde soyut durumları anlamlandırmada öğrencilerin problem yaşadıkları belirtilmektedir (Yıldırım, Yalçın, Şensoy \& Akçay, 2008). Bununla birlikte öğrencilerin elektrik konusuyla ilgili alan bilgilerinin yetersizliğinden kaynaklı olarak doğru tasarımı yapamadıkları ve zorlandıkları da belirtilmiştir (Delen \& Uzun, 2018). Benzer şekilde Aydın ve Karslı Baydere (2019)'nin yedinci sinıf öğrencileriyle yaptığı çalışmasında da STEM etkinliklerinin uygulandığı sürecin sonunda öğrenciler birtakım zorluklar yaşamışlardır.

Yapılan araştırmamızın sonuçları dikkate alındığında; öğrencilerin öğretim ortamlarında günlük yaşantıdaki deneyimlerini tetikleyebileceği ve onların bireysel yeteneklerini geliştirecek ve akademik başarılarının gelişimine katkı sağlayacak uygulamalı etkinliklere ihtiyaç olduğu düşünülmektedir. Öğretim ortamlarında yapılan etkinliklerin öğrencilerin disiplinlerarası ilişkiler kurmasına firsat verici, öğretici ve eğitici etkinlikler olmasına dikkat edilmelidir. Bu şekilde geçirilen uygulama süreçleri öğrencilerin motivasyonlarını olumlu yönde etkileyecektir. Ayrıca bu araştırma sürecinde elde ettiğimiz farklı bir husus da STEM temelli uygulamalar sırasında yürütülen öğretmenöğrenci interaktif etkileşiminin öğrencilerde var olan yanlış kavramaların ortaya çıkarılmasında da yararlı olabileceği konusudur.

\section{Kaynakça}

Akdağ, M., \& Tok, H. (2010). Geleneksel öğretim ile powerpoint sunum destekli öğretimin öğrenci erişisine etkisi. Ĕgitim ve Bilim, 33(147), 26-34.

Akgündüz, D., Aydeniz, M., Çakmakçı, G., Çavaş, B., Çorlu, M. S., Öner, T., \& Özdemir, S. (2015). STEM eğitimi Türkiye raporu: Günün modası mı yoksa gereksinim mi? [A report on STEM Education in Turkey: A provisional agenda or a necessity?]. İstanbul Aydın Üniversitesi STEM Merkezi ve Eğitim Fakültesi. https://www.aydin.edu.tr/trtr/akademik/fakulteler/egitim/Documents/STEM\%20E\%C4\%9Fitimi\%20T\%C3\%BCrkiye \%20Raporu.pdf

Anderman, E. M., \& Midgley, C. (1997). Changes in achievement goal orientations, perceived academic competence, and grades across the transition to middle level schools. $\begin{array}{llll}\text { Contemporary Educational 269-298. } & \text { 26 }\end{array}$ https://doi.org/10.1006/ceps.1996.0926

Arık, A. (1996). Motivasyon ve heyecana giriş. Çantay Kitabevi.

Avan, Ç., Gülgün, C., Yılmaz, A., \& Doğanay, K. (2019) STEM eğitiminde okul dış1 öğrenme ortamları: kastamonu bilim kampı. Bilim, Teknoloji, Mühendislik, Matematik ve Sanat (JSTEAM) Ĕ̈itim Dergisi, 2(1), 39-51. 
Ayar, M. C. (2015). First-hand experience with engineering design and career interest in engineering: an informal STEM education case study. Educational Sciences: Theory and Practice, 15(6), 1655-1675. https://doi.org/10.12738/estp.2015.6.0134

Aydın, E., \& Karslı Baydereı, F. (2019). Yedinci sınıf öğrencilerinin STEM etkinlikleri hakkındaki görüşleri: karışımların ayrıştırılması örneği. Ondokuz Mayıs University Journal of Education, 38(1), 35-52. https://doi.org/10.7822/omuefd.439843

Baran, E., Canbazoğlu-Bilici, S., \& Mesutoğlu, C. (2017). Fen, teknoloji, mühendislik ve matematik (FeTeMM) spotu geliştirme etkinliği. Journal of Inquiry Based Activities, 5(2), 60-69.

Buyruk, B., \& Korkmaz, Ö. (2016). FeTeMM farkındalık ölçeği (FFÖ): geçerlik ve güvenirlik çalışması. Journal of Turkish Science Education, 11(1), 3-23. https://doi.org/10.12973/tused.10179a

Büyüköztürk, S. (2013). Sosyal bilimler için veri analizi el kitabı (18. Baskı). Pegem Akademi Yayıncilik.

Çavaş, B., Bulut, Ç., Holbrook, J., \& Rannikmae, M. (2013). Fen eğitimine mühendislik odaklı bir yaklaşım: ENGINEER projesi ve uygulamaları. Fen Bilimleri Öğretimi Dergisi, 1(1), 12-22.

Çorlu, M. S., Capraro, R. M., \& Capraro, M. M. (2014). Introducing STEM education: Implications for educating our teachers in the age of innovation. Education and Science, 39(171), 74-85.

Dede, Y., \& Yaman, S. (2008). Fen öğrenmeye yönelik motivasyon ölçeği: Geçerlik ve güvenirlik çalışması. Necatibey Eğitim Fakültesi Elektronik Fen ve Matematik Eğitimi Dergisi, 2(1), 19-37.

Delen, I., \& Uzun, S. (2018). Evaluating STEM based learning environments created by mathematics pre-service teachers. Hacettepe Universitesi Egitim Fakultesi Dergisi-Hacettepe University Journal of Education, 33(3), 617-630.

Demircioğlu, G., Özmen, H., \& Demircioğlu, H. (2004). Bütünleştirici öğrenme kuramına dayalı olarak geliştirilen etkinliklerin uygulanmasının etkililiğinin araştırılması. Türk Fen Ĕgitimi Dergisi, $\quad 1(1), \quad 21-35 . \quad$ file:///C:/Users/EEF/Downloads/34-Article\%20Text-30-1-1020191106.pdf

Elmalı, Ş., \& Balkan Kıyıcı, F. (2017). Türkiye'de yayınlanmış FeTeMM eğitimi ile ilgili çalışmaların incelenmesi. Sakarya University Journal of Education, 7(3), 684-696. https://doi.org/10.19126/suje.322791

Freedman, M. P. (1997). Relationship among laboratory instruction, attitude toward science, and achievement in science knowledge. Journal of Research in Science Teaching, 34(4), 343357.

Fortus, D., \& Vedder-Weiss, D. (2014). Measuring students' continuing motivation for science learning. Journal of Research in Science Teaching, 51(4), 497-522. https://doi.org/10.1002/tea.21136

Garcia, T., \& Pintrich, P. R. (1992). Critical thinking and its relationship to motivation, learning strategies, and classroom experience. Paper presented at the Annual Meeting of the American Psychological Association, Washington, DC, August.

Gelen, İ. (2017). P21-Program ve öğretimde 21. yüzy1l beceri çerçeveleri (ABD Uygulamaları). Disiplinlerarası Eğitim Araştırmaları Dergisi, 1(2), 15-29. E-ISSN: 26022516 
Gelici, Ö., \& Bilgin, İ. (2011). İşbirlikli öğrenme tekniklerinin tanıtımı ve öğrenci görüşlerinin incelenmesi. Adlyaman Universitesi Fen Bilimleri Dergisi, 1(1), 40-70.

Gökbayrak, S., \& Karışan, D. (2017). Altıncı sınıf öğrencilerinin FeTeMM temelli etkinlikler hakkındaki görüşlerinin incelenmesi. Alan Eğitimi Araştırmaları Dergisi (ALEG), 3(1), 2640 .

Green, A. (2012). The integration of engineering design projects into the secondary science classroom [Yüksek Lisans Tezi, Michigan StateUniversity]. ProQuest

Hallak, F., K., Armoni, M., \& Ben-Ari, M. (2015). Students' attitudes and motivation during robotics activities. WiPSCE '15 Proceedings of the Workshop in Primary and Secondary Computing Education, 9-11 November 2015, London, UK.

Harlen, W., \& Deakin Crick, R. (2003). Testing and motivation for learning. Assessment in Education: $\quad$ Principles, $\quad$ Policy \& $\quad$ Practice, 10(2), 169-207. https://doi.org/10.1080/0969594032000121270

Herdem, K., \& Ünal, İ. (2018). STEM eğitimi üzerine yapılan çalışmaların analizi: bir meta-sentez çalışması. Marmara Üniversitesi Atatürk Eğitim Fakültesi Eğitim Bilimleri Dergisi, 48(48), 145-163. https://doi.org/10.15285/maruaebd.381417

Huss-Keeler, R., Peters, M., \& Moss, J. M. (2013). Motivation for attending higher education from the perspective of early care and education professionals. Journal of Early Childhood Teacher Education, 34(2), 121-139. https://doi.org/10.1080/10901027.2013.787475

Kang, J., Ju, E. J., \& Jang, S. (2013). The Effect of Science-based STEAM program using a portfolio on elementary students' formation of science concepts. Elementary Science Education, 32(4), 593-606.

Kang, M., Kim, J., \& Kim, Y. (2013). Learning outcomes of the teacher training program for STEAM education. Korean Journal of the Learning Sciences, 7(2), 18-28.

Karahan, E., Canbazoğlu Bilici, S., \& Ünal, A. (2015). Integration of mediadesignprocesses in science, technology, engineering, and mathematics (STEM) education. Eurasian Journal of Educational Research, 15(60), 221-240. https://doi.org/10.14689/ejer.2015.60.15

Karakaya, F., Avgın, S. S., \& Yılmaz, M. (2018). Ortaokul öğrencilerinin fen-teknoloji-mühendislikmatematik (FeTeMM) mesleklerine olan ilgileri. Ihlara Eğitim Araştırmaları Dergisi, 3(1), 36-53. e-ISSN 2528-9632

Khamis, V., Dukmak, S., \& Elhoweris, H. (2008). Factors affecting the motivation to learn among United Arab Emirates middle and high school students. Educational Studies, 34(3), 191-200. https://doi.org/10.1080/03055690701811297

Koçakoğlu, M. (2010). Probleme dayalı öğrenme: Yapılandırmacılığın özü. Milli Eğitim Dergisi, 40(188) 68-82.

Kong, Y. T., \& In-Cheol, J. (2014). The effect of subject based STEAM activity programs on scientific attitude, self efficacy, and motivation for scientific learning. International Information Institute (Tokyo). Information, 17(8), 3629. ISSN 1343-4500

Kuvaç, M., \& Koç Sarı, I. (2018). E-STEM STEM öğretmenleri için çevre konularına yönelik ortaokul etkinlik kitabı. Anı Yayınc1l1k.

Kuyper, H., van der Werf, M. P. C., \& Lubbers, M. J. (2000). Motivation, meta-cognition and selfregulation as predictors of long term educational attainment. Educational Research and Evaluation, 6(3), 181-201. https://doi.org/10.1076/1380-3611(200009)6:3;1-A;FT181 
Küçük, S., \& Şişman, B. (2017). Birebir robotik öğretiminde öğreticilerin deneyimleri. İlköğretim Online, 16(1), 312-325.

Lee, O., \& Brophy, J. (1996). Motivational patterns observed in sixth-grade science classrooms. Journal of Research in Science Teaching, 33(3), 585-610. https://doi.org/10.1002/(sici)1098-2736(199603)33:3<303::aid-tea4>3.0.co;2-x

Li, P., \& Pan, G. (2009). The relationship between motivation and achievement - a survey of the study motivation of English majors in Qingdao Agricultural University. English Language Teaching, 2(1), 123-128. https://doi.org/10.5539/elt.v2n1p123

Martin, B. L., \& Brigss, L. J. (1986). The affective and cognitive domains: Integration for instruction and research. Educational Technology Publications.

Means, B., Wang, H., Young, V., Peters, V. L., \& Lynch, S. J. (2016). STEM focused high schools as a strategy for enhancing readiness for postsecondary STEM programs. Journal of Research in Science Teaching, 53(5), 709-736. https://doi.org/10.1002/tea.21313

MEB. (2019). Fen Bilimleri 7 ortaokul ve imam hatip ortaokulu ders kitabl. Devlet Kitaplar1 Birinci Bask1.

MEB. (2018). Fen bilimleri dersi ögretim programı (ilkokul ve ortaokul 3, 4, 5, 6, 7 ve 8. sinıflar). http://mufredat.meb.gov.tr/Dosyalar/201812312311937-

FEN\%20B\%C4\%B0L\%C4\%B0MLER\%C4\%B0\%20\%C3\%96\%C4\%9ERET\%C4\%B0M \%20PROGRAMI2018.pdf

Merrill, C. (2009). The future of TE masters degrees: STEM. Presentation at the 70th Annual International Technology Education Association Conference, Louisville, Kentucky.

Miles, M. B., \& Huberman, A. M. (1994).Qualitative data analysis: An expanded sourcebook. Sage.

Mohr-Schroeder, M. J., Jackson, C., Miller, M., Walcott, B., Little, D. L., Speler, L., ... \& Schroeder, D. C. (2014). Developing middle school students' interests in STEM via summer learning experiences: See Blue STEM Camp. School Science and Mathematics, 114(6), 291-301. https://doi.org/10.1111/ssm.12079

Moore, T. J., Stohlmann, M. S., Wang, H. H., Tank, K. M., \& Roehrig, G. H. (2014). Implementation and integration of engineering in K-12 STEM education. In J. Strobel, S., Purzer, \& M. Cardella (Eds.), Engineering in precollege settings: Research into practice. PurduePress.

NRC. (2011). Successful K-12 STEM education: Identifying effective approaches in science, technology, engineering, and mathematics. National Academy Press.

Özdemir, M. (2010). Nitel very analizi: Sosyal bilimlerde yöntem bilim sorunsalı üzerine bir çalışma. Eskişehir Osmangazi Üniversitesi Sosyal Bilimler Dergisi, 11(1), 323-343.

Park, S. J., \& Yoo, P. K. (2013). The effects of the learning motive, interest and science process skills using the 'Light' unit on science-based STEAM. Journal of Korean Elementary Science Education, 32(3), 225-238.

Sar1, U., \& Yazıc1, Y. Y. (2018). STEM eğitiminin fen ögrenimine yönelik motivasyona etkisi. Uluslararası Öğrenme, Öğretim ve Ĕgitim Araştırmaları (International Learning, Teaching and Educational Research Congress - ILTER). 6-8 September 2018, Amasya.

Science Fair Central. (2018). Companies need to "think outside the box" when it comes to packaging design. http://www.sciencefaircentral.com/sites/default/files/activities/home-depot-makercorner-designed-delivery.pdf 
STEM Temelli Uygulamaların Ortaokul Öğrencilerinin Fen Öğrenmeye Yönelik...

Science Fair Central (2018). Lemon powered. https://www.sciencefaircentral.com/sites/default/files/activities/home-depot-maker-cornerlemon-powered_0.pdf

Sencar, S., Y1lmaz, E. E., \& Eryılmaz, A. (2001). High school students' misconceptions about simple electric circuits. Hacettepe Üniversitesi Eğitim Fakültesi Dergisi, 21, 113-120.

Smith, J., \& Karr-Kidwell, P. J. (2000). The interdisciplinary curriculum: a literary review and a manual for administrators and teachers. http://files.eric.ed.gov/fulltext/ED443172.pdf adresinden edinilmiştir.

Spitzer, D. (1996). Motivation: The neglected factor in instructional design. Educational Technology, 36(3), 45-49. http://www.jstor.com/stable/44428339

Teoh, S. H., Koo, A. C., \& Singh, P. (2010). Extracting factors for students' motivation in studying mathematics. International Journal of Mathematical Education in Science and Technology, 41(6), 711-724. https://doi.org/10.1080/00207391003675190

The NASA BEST Activities Guide (2011). An educator's guide to the engineering design process grades 6-8. https://www.nasa.gov/pdf/530250main_6to8NBSGuide.pdf

Thomas, T. A. (2014). Elementary teachers' receptivity to integrated science, technology, engineering, and mathematics (STEM) education in the elementary grades (Publication No. 3625770) [Doctoral dissertation, University of Nevada]. ProQuest.

Tuan, H. L., Chin, C. C., \& Shieh, S. H. (2005). The development of a questionnaire to measure students' motivation towards science learning. International Journal of Science Education, 27(6), 639-654. https://doi.org/10.1080/0950069042000323737

Uğraş, M. (2018). The effects of STEM activities on STEM attitudes, scientific creativity and motivation beliefs of the students and their views on STEM education. International Online Journal of Educational Sciences, 10(5), 165-182. https://doi.org/10.15345/iojes.2018.05.012

Uluyol, Ç., \& Eryılmaz, S. (2015). 21. yüzyıl becerileri işı̆̆ında fatih projesi değerlendirmesi. Gazi Üniversitesi Gazi Eğitim Fakültesi Dergisi, 35(2), 209-229.

Van De Gaer, E., Fraine, B. D., Pustjens, H., Damme, J. V., Munter, A. D., \& Onghena, P. (2009). School effects on the development of motivation toward learning tasks and the development of academic self-concept in secondary education: a multivariate latent growth curve approach. School Effectivenessand School Improvement, 20(2), 235-253. https://doi.org/10.1080/09243450902883920

Vedder-Weiss, D., \& Fortus, D. (2010). Adolescents' declining motivation to learn science: Inevitable or not? Journal of Research in ScienceTeaching, 48(2), $199-216$. https://doi.org/10.1002/tea.20398

Vennix, J., den Brok, P., \& Taconis, R. (2018). Do outreach activities in secondary STEM education motivate students and improve their attitudes towards STEM? International Journal of Science Education, 1-21. https://doi.org/10.1080/09500693.2018.1473659

Visser-Wijnveen, G., Stes, A., \& Petegem, P. V. (2012). Development and validation of a questionnaire measuring teachers' motivations for teaching in higher education. Higher Education, 64(3), 421-436. https://doi.org/10.1007/s10734-011-9502-3

Wang, H. (2012). A New era of science education: science teachers ' perceptions and classroom practices of science, technology, engineering, and mathematics (STEM) integration 


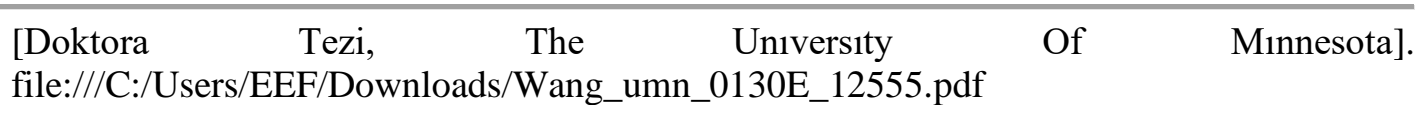

Wang, H. H., Moore, T. J., Roehrig, G. H., \& Park, M. S. (2011). STEM integration: teacher perceptions and practice. Journal of Pre-Collage Engineering Education Research, 1(2), 113. https://doi.org/10.5703/1288284314636

Wigfield, A., \& Wentzel, K. R. (2007). Introduction to motivation at school: Interventions that work. Educational Psychologist, 42(4), 191-196. https://doi.org/10.1080/00461520701621038

Wolters, C. A. (1999). The relation between high school students' motivational regulation and their use of learning strategies, effort, and classroom performance. Learning and Individual Differences, 11(3), 281-300. https://doi.org/10.1016/S1041-6080(99)80004-1

Yalaki, Y. (2016). Etkinliklerle bilimin doğası ögretimi 5. 6. 7. ve 8. sinıflar. Pegem Akademi.

Yıldırım, A., \& Şimşek, H. (2005). Sosyal bilimlerde nitel araştırma yöntemleri. Seçkin Yayıncılık.

Yıldırım, H. İ., Yalçın, N., Şensoy, Ö., \& Akçay, S. (2008). İlköğretim 6., 7. ve 8. sınıf öğrencilerinin elektrik akımı konusunda sahip oldukları kavram yanılgıları. Kastamonu Ĕgitim Dergisi, 16(11), 67-82.

Yılmaz, H., \& Çavaş, P. H. (2007). Reliability and validity study of the students' Motivation toward Science Learning (SMTSL) questionnaire. Elementary Education Online, 6(3), 430-440. http://ilkogretim-online.org.tr 